\title{
LA DESAPARICIÓN \\ FORZADA EN EL CONTEXTO \\ DE JUDICIALIZACIÓN Y \\ REPARACIÓN DE VALORES \\ SUPERIORES DESDE LA \\ ÉTICA DE JUSTICIA DE \\ MICHAEL SANDEL
}

Juan Guillermo Durán Mantilla

Jaime Alberto Sandoval Mesa

Álvaro Hernán Moreno Durán 



\title{
LA DESAPARICIÓN FORZADA EN EL CONTEXTO DE JUDICIALIZACIÓN Y REPARACIÓN DE VALORES SUPERIORES DESDE LA ÉTICA DE JUSTICIA DE MICHAEL SANDEL
}

\author{
Juan Guillermo Durán Mantilla \\ Jaime Alberto Sandoval Mesa \\ Álvaro Hernán Moreno Durán \\ UNIVERSIDAD SANTO TOMAS
}

\section{Resumen}

En el contexto del conflicto armado en Colombia se han presentado múltiples violaciones de derechos humanos, que han determinado la persecución de las más graves conductas internacionales, entre ellas, la desaparición forzada. Desde la perspectiva que vamos a abordar, en el texto de Michael Sandel titulado Justicia ¿Hacemos lo que debemos?, más allá de los problemas jurídicos y de política criminal que el hecho encarna, veremos una reflexión ética acerca del problema, sin dejar de confrontar sus exigencias legales. El presente artículo es un análisis ius filosófico sobre los valores y deberes de protección del ciudadano que se afectan y comprometen la labor del Estado en la persecución y represión del crimen de desaparición forzada, a partir de sus elementos de producción de la conducta. Para tal efecto se desarrolla una investigación hermenéutica analítica de tipo descriptivo y propositiva.

Palabras clave: desaparición forzada, amparo judicial, libertad, dignidad humana, persecución judicial.

Artículo de investigación basado en el proyecto "La construcción del contexto en los elementos del crimen de desaparición forzada. Interpretación de la norma interna e internacional". Cod. 2018003. 
Los autores: Juan Guillermo Durán Mantilla, doctor en Derecho, profesor investigador de la Facultad de Derecho de la Universidad Santo Tomás. Correo electrónico: natanaelernesto@hotmail.com Jaime Alberto Sandoval Mesa, doctor en Derecho, profesor investigador de la Facultad de Derecho de la Universidad Santo Tomás. Correo electrónico: jaimesandoval@usantotomas.edu.co Álvaro Hernán Moreno Durán, doctor en Sociología. profesor investigador de la Facultad de Derecho de la Universidad Santo Tomás. Correo electrónico: alvaromoreno@usantotomas.edu.co

Recibido: 10 de febrero de 2020; evaluado: 14 de marzo de 2021; aceptado: 8 de abril de 2021 


\title{
ENFORCED DISAPPEARANCE IN THE CONTEXT OF JUDICIALIZATION AND REPARATION OF SUPERIOR VALUES FROM MICHAEL SANDEL'S ETHICS OF JUSTICE
}

\author{
Juan Guillermo Durán Mantilla \\ Jaime Alberto Sandoval Mesa \\ Álvaro Hernán Moreno Durán \\ Universidad Santo Tomas
}

\begin{abstract}
In the context of the armed conflict in Colombia, multiple human rights violations have occurred, which have determined the prosecution of the most serious international conducts, including enforced disappearance. From this paper's approach, in the text of Michael Sandel, entitled Justice: Do we do what we must?, beyond the legal and criminal policy problems that the fact embodies, an ethical reflection on the problem will be made, without ceasing to confront its legal requirements. This article is a philosophical analysis on the values and protection duties of the citizen that affect and compromise the work of the State in the prosecution and repression of the crime of enforced disappearance, based on the elements of production of the conduct. To this end, an analytical hermeneutic research of descriptive and propositive type is carried out.
\end{abstract}

Keywords: enforced disappearance, judicial protection, freedom, human dignity, judicial prosecution. 
The authors: Juan Guillermo Durán Mantilla, PhD in Law, research professor at the Faculty of Law of Universidad Santo Tomás. E-mail: natanaelernesto@hotmail.com

Jaime Alberto Sandoval Mesa, PhD in Law, research professor at the Faculty of Law of Universidad Santo Tomás. E-mail: jaimesandoval@usantotomas.edu.co

Álvaro Hernán Moreno Durán, Ph.D. in Sociology, research professor at Universidad Santo Tomás Law School. E-mail: alvaromoreno@usantotomas.edu.co

Received: February 10, 2020; evaluated: March 14, 2021; accepted: April 8, 2021 


\title{
O DESAPARECIMENTO FORÇADO NO CONTEXTO DE JUDICIALIZAÇÃO E REPARAÇÃO DE VALORES SUPERIORES A PARTIR DA ÉTICA DE JUSTIÇA DE MICHAEL SANDEL
}

\author{
Juan Guillermo Durán Mantilla \\ Jaime Alberto Sandoval Mesa \\ Álvaro Hernán Moreno Durán \\ Universidad Santo Tomas
}

\section{Resumo}

No contexto do conflito armado na Colômbia, são apresentadas múltiplas violações dos direitos humanos que vêm determinando a persecução das mais graves condutas internacionais, entre elas, o desaparecimento forçado. Sob a perspectiva que abordamos, no texto de Michael Sandel intitulado Justiça: o que é fazer a coisa certa?, mais além dos problemas jurídicos e de política criminal que o fato implica, vemos uma reflexão ética sobre o problema, sem deixar de confrontar suas exigências legais. Neste artigo, faz-se uma análise jus filosófica dos valores e dos deveres de proteção do cidadão que são afetados e comprometem o trabalho do Estado na persecução e na repressão do crime de desaparecimento forçado a partir de seus elementos de produção da conduta. Para isso, é desenvolvida uma pesquisa hermenêutica analítica de tipo descritivo e propositivo.

Palavras-chave: desaparecimento forçado, amparo judicial, liberdade, dignidade humana, persecução judicial. 
Os autores: Juan Guillermo Durán Mantilla, doutor em Direito, professor pesquisador da Faculdade de Direito da Universidad Santo Tomás, Colômbia. Correio eletrônico: natanaelernesto@hotmail.com Jaime Alberto Sandoval Mesa, doutor em Direito, professor pesquisador da Faculdade de Direito da Universidad Santo Tomás, Colômbia. Correio eletrônico: jaimesandoval@usantotomas.edu.co Álvaro Hernán Moreno Durán, doutor em Sociologia, professor pesquisador da Faculdade de Direito da Universidad Santo Tomás. Correio eletrônico: alvaromoreno@usantotomas.edu.co

Recebido: 10 de fevereiro de 2020; avaliado: 14 de março de 2021; aceito: 8 de abril de 2021 


\section{Introducción}

El problema de la desaparición forzada se centra en un espinoso y doloroso tema que implica inmiscuirse en la ética, más allá o más acá del derecho positivo, pues la ética es una arista de la vida humana de la que no podemos hacer caso omiso. Por cierto, en la vida humana, derecho y ética guardan estrecha relación. ${ }^{1}$

Para ver esa cercanía, nos hemos valido de un filósofo actual, Michael Sandel, quien en su obra Justicia. ¿Hacemos lo que debemos? aborda distintas escuelas para mostrar diversas concepciones (el liberalismo, el comunitarismo, el aristotelismo, el kantismo, etc.) y así ilustrar a los lectores sobre la importancia de la reflexión ética. ${ }^{2}$ Desde la visión de Sandel podemos analizar los fundamentos que revelan por qué es importante el proceso de judicialización, penalización y verdad en la desaparición forzada. Es posible que este sea el delito de mayor atención en la determinación de los hechos que han afectado a las víctimas del conflicto armado. Además, por su naturaleza, no solo de lesa humanidad, sino de ejecución permanente, todavía se encuentran vigentes las situaciones asociadas a estos ilícitos, razón que permite resolver los actos de impunidad contemporáneos, es decir, en el delito analizado, el amparo judicial es una figura que permite valorar el último acto del delito para iniciar la investigación y valorar su prescripción. Adicionalmente, desde la perspectiva analizada de Sandel, se observa la razón por la cual resulta imperioso abordar con seriedad la judicialización y el castigo de ese delito en el contexto de la justicia transicional contemporánea derivada de los acuerdos de paz de 2016.

\section{Los deberes de la ética y el reconocimiento de la historia del desaparecido}

Valiéndonos del trabajo de Sandel podemos abordar éticamente la desaparición forzada e iluminar, de alguna manera, el derecho positivo. Descubriremos que debe ser examinada desde la óptica ética para hacerle un juicio imprescindible y fundamental del derecho. Nos hemos basado, de manera desenfadada, en algunos

\footnotetext{
La relación entre ética y derecho es uno de los capítulos trascendentales de la filosofía del derecho y ha trasegado por posiciones de separación y de cercanía; hoy en día, con raíces en Aristóteles, encontramos cercanía, lo cual se observa en iusfilósofos como Alexy. Robert Alexy, La institucionalización de la justicia, 3a ed. (Granada: Comares, 2005).

2 Así lo expresa: "Este libro no es una historia de las ideas, sino un viaje por la reflexión moral y política. Su meta no consiste en mostrar quién ha influido en quién [...], sino invitar a los lectores a que sometan sus propios puntos de vista sobre la justicia a examen crítico, a que determinen qué piensan y porqué lo piensan". Michael Sandel, Justicia. ¿Hacemos lo que debemos? (Barcelona: Debate, 2011), 41.
} 
apartes de su obra arriba mencionada, porque hemos creído que guardan relación con el tema estudiado.

En el primer capítulo, intitulado "Hacer lo que es debido. Resonancia de la ética kantiana basada en el deber por el deber" aborda la condecoración Corazón Púrpura, de Estados Unidos, para los héroes de guerra; debate Sandel si debe otorgarse a quienes han sufrido consecuencias físicas o si también abarca las consecuencias psíquicas de la guerra.

El juicio de Sandel, a nuestro parecer, es que la insignia debe darse incluso a los afectados psíquicamente. ${ }^{3}$ Muy a su estilo, deja abiertas las puertas — como lo recordamos atrás - a la valoración ética del lector; quisiéramos adelantarnos a Sandel y hacer nuestro propio juicio para este tipo de condecoración: la balanza se inclina por tener en cuenta aun las consecuencias psíquicas de los combatientes ${ }^{4}$.

¿Qué tiene que ver esto con la desaparición forzada? Bien porque afecta el cuerpo de la víctima (al causar la muerte física) y también el alma de los familiares y de la sociedad (al menos, a una parte de ella), razón por la cual debe ser censurada éticamente, porque impacta al cuerpo y al espíritu. Se trata de una valoración ética por la falta de capacidad del Estado de reprimir la conducta. ${ }^{5}$ Podemos partir del Artículo II de la Convención sobre desaparición forzada de personas, de junio de 1994, que sostiene que este delito se comete por la privación de la libertad de una o más personas, es decir, el primer atentado es ocultar a la persona raptada, cualquiera que fuera su forma. Y allí se reitera que esta puede ser ejecutada por agentes del Estado o por personas o grupos de personas que actúen con cualquier forma de autorización, que significa liberalidad, apoyo o aquiescencia del Estado. ${ }^{6}$

Pues bien, estos actos revelan que la mentira del victimario o la indefensión de la víctima no puede quedar rezagada ante los argumentos de la inoperancia estatal

Sandel, Justicia, 19-21.

4 La verdad, no sabemos por qué esta temática se incluye en la ética del deber kantiano; quizá porque, hasta ahora, solo se circunscribe a un tipo de consecuencia (físico), como si envolviera todo el deber en una guerra, pero buscando abrir el debate a otro tipo de consideración ética que Sandel irá desarrollando en Justicia, vista de manera global en su texto.

5 Hugo Saidiza y Jorge Enrique Carvajal, "Crisis del Estado de derecho en Colombia: un análisis desde la perspectiva de la legislación penal”, IUSTA, núm. 44 (2016): 33, https://revistas.usantotomas.edu.co/index. php/iusta/article/view/3074 (acceso enero 3, 2018).

6 Jaime Sandoval y Juan Durán, "La construcción del contexto en los elementos del crimen de desaparición forzada. Interpretación de la norma interna e internacional" (Proyecto para el fomento de la investigación y la innovación, Universidad Santo Tomás, 2019), 6-7. 
o la violación al derecho internacional de los derechos humanos o del derecho internacional humanitario en una supuesta guerra justa. En términos jurídicos, estas acciones indican que el primer acto perpetrado, en este delito, vulnera, en primer lugar, el derecho a la libertad, a la vida e integridad personal. ${ }^{7}$ En seguida aparece el segundo acto, que se origina en la negativa de dar información acerca del paradero de la persona e incluso de reconocer la privación de la libertad. En este segundo acto se vulneran el derecho al amparo judicial y las garantías procesales. ${ }^{8}$

Por favor, tengamos esto en cuenta a la hora de examinar las otras posiciones en su conjunto. Dejemos esta calificación, por ahora, en salmuera. Adelantemos la consideración de aberrante de la desaparición forzada, si se sopesan esos argumentos, junto con estas definiciones iniciales que provienen del sistema de los derechos humanos.

\section{La obligatoriedad de reprimir la desaparición forzada}

Sandel estaría de acuerdo con la obligatoriedad de represión, toda vez que, en su línea de exposición en el libro que venimos siguiendo, más que soluciones éticas, Sandel hace planteamientos para estimular la reflexión ética. Sería muy amplia la reflexión y, para él, lo forzado de la desaparición violenta la libertad. En este campo concreto, Sandel estaría en contra de esta conducta, incluso, por ser mucho más grave que el ejemplo que analiza en el texto, relativo a la condena al trabajo forzado.

En cuanto al concepto legal, el delito consagrado en Colombia mantiene la forma mencionada, aunque lo amplia para aquellos casos en los que no se trata de la actuación de agentes estatales, sino también cuando la cometen particulares, máxime en el escenario del conflicto armado. ${ }^{9}$ Desde la ética de Sandel sería adecuado que todo aquel que violente la libertad en este sentido fuera reprobado por el sistema de justicia. ${ }^{10}$

En esta línea de agravantes de la conducta, si en el caso se comete el crimen mediante agentes del Estado o si se produce la muerte de la persona cautiva, entre otras situaciones, también se afecta la libertad, en el sentido de Sandel. De igual forma,

Corte Interamericana de Derechos Humanos, Cuadernillo de jurisprudencia de la Corte Interamericana de Derechos Humanos $N^{o}$ 6: desaparición forzada (San José: Autor, 2020), 21-41; Sandoval y Durán, "La construcción", 6-7.

8 Sandoval y Durán, "La construcción", 6-7.

9 República de Colombia, Constitución Politica (Bogotá: Legis, 1991), art. 165.

10 Sandoval y Durán, "La construcción", 6-7. 
el Artículo 166 CP describe los atenuantes si los procesados dan información con respecto al paradero de la víctima o sobre sus restos y demás aspectos.

Esta descripción del tipo penal avanzado también sirve de base para el referente a la moral kantiana que aparece en este acápite, toda vez que encontramos el siguiente subtítulo: "Segunda versión del imperativo categórico: tratar a las personas como fines". ${ }^{11}$ Esta afirmación nos sirve para examinar la eticidad en el castigo de la desaparición forzada. La consideración de la persona como "fin" para Kant está resumida así por Sandel: el respeto kantiano es un respeto a la humanidad en cuanto tal, por la capacidad racional que reside, indiferenciada, en todos. Resulta lesivo de la dignidad humana el sistema tanto básico como de agravantes cuando se ejecuta la conducta de la desaparición forzada.

Esto explica por qué violarlo en mi propio caso es tan rechazable como violarlo en otros. Explica, además, por qué el principio kantiano del respeto se acomoda a las doctrinas de los derechos humanos universales. Para Kant, la justicia requiere que respetemos los derechos humanos de cualquier persona, vida donde viva o la conozcamos poco o mucho, simplemente porque es un ser humano, capaz de servirse de la razón y, por lo tanto, es digna de respeto. ${ }^{12}$ Con mayor razón en el tipo de la desaparición forzada.

Incluso este factor se vislumbra en la prohibición internacional que define una moral universal para su represión, puesto que el delito de desaparición forzada se encuentra tipificado en el Artículo 7 del Estatuto de Roma de 1998, normatividad que la considera crimen internacional de lesa humanidad. Esta tradición también deviene de los sistemas de derechos humanos que en múltiples decisiones así lo han considerado, como en Rodríguez Vera y otros (desaparecidos del Palacio de Justicia) vs. Colombia. ${ }^{13}$

Como puede verse, esta perspectiva internacional señala que la afirmación basada en el racionalismo filosófico de Kant sustenta la dignidad humana en la racionalidad, cosa que no compartimos del todo por ser solo un elemento de la dignidad humana, pero nos puede servir para nuestro análisis ético de la desaparición forzada: nos

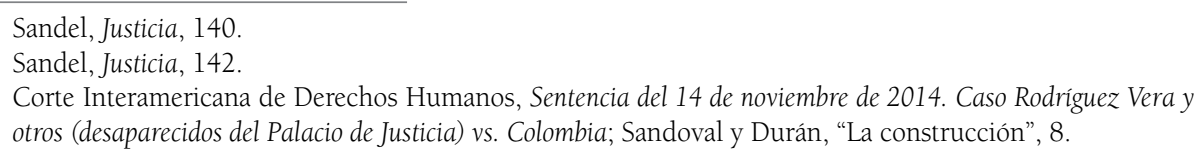


muestra que ella viola claramente dicha dignidad, así sea por violar la racionalidad (creemos, ante todo, del victimario).

En diversos documentos y pronunciamientos como el analizado se observa la necesidad de judicialización de los posibles autores, la revelación de los hechos motivo de la desaparición y la reparación de las víctimas. En estos casos se examina el valor probatorio que surge de estos mecanismos de persecución de violaciones graves de derechos humanos que concurren en estos delitos.

Vamos viendo a las claras hacia dónde se inclina la balanza de la desaparición forzada en el pensamiento sandeliano. Al ser la persona un "fin" en sí misma, no puede haber otros fines que la suplanten y, en consecuencia, la desaparición forzada es condenable enteramente; desde luego, a continuación se abre la pregunta acerca de si la persona humana es el único fin, si no hay otros fines quizá más elevados que la misma persona (como podría ser el bien común) o, al menos, fines equiparables, como podrían ser las otras personas, frente a lo cual el deber de igualdad personal exigiría una ponderación de los derechos de los demás, tesis que expone hoy en día Robert Alexy. ${ }^{14}$ Entonces, desde la comisión de la conducta, en el caso de la desaparición forzada, no basta con su descripción, porque allí solo advertimos la violación de la dignidad humana; se requiere su judicialización para perseguir otros valores superiores de la sociedad (bien común).

\section{La desaparición y el propósito de judicialización}

En primer lugar, en la desaparición forzada, a nuestro juicio, se viola la esencia del respeto a la vida humana en condiciones de normalidad y se atenta contra el fin de la convivencia pacífica, de la hermandad, de la solidaridad. Desde el concepto de Aristóteles —ética de la virtud—, según el cual el individuo está llamado a ser más, a crecer, y ese crecimiento se logra con la virtud, recuerda Sandel que "para definir los derechos hemos de determinar el telos (el propósito, fin o naturaleza esencial) de la práctica en cuestión". ${ }^{15}$

En la desaparición forzada, los valores que se exponen son la libertad personal, la integridad y la vida humana. Piénsese con serenidad, lejos del apasionamiento ideológico, y se verá que es así sin mayores profundizaciones (los hechos y las ideas

14 Alexy, La institucionalización de la justicia, 65-66.
15 Sandel, Justicia, 212. 
notorias no necesitan prueba; lamentablemente, como decía Chesterton, lo que ha perdido el individuo actual, más que la fe, es la razón). Por eso la desaparición forzada está censurada en los ordenamientos jurídicos tanto internos como internacionales; desde el punto de vista analizado de Sandel, se vulnera la esencia de las cosas, que, en este caso, representa la dignidad humana y la libertad.

Sobre los primeros aspectos que objetivamente se vulneran con la desaparición forzada aparece el concepto de protección estatal a las personas; el valor de su persecución radica en la privación del amparo judicial de la víctima, cuando es objeto de rapto. En este caso se le niega la posibilidad de denunciar la privación ilegal de su libertad. Otro tanto lo constituye que se sepa o no del hallazgo de los restos humanos objeto de la desaparición, en contraposición con la tendencia que indica la necesidad de hallazgo efectivo de restos humanos o de la víctima. ${ }^{16}$ Desde la perspectiva analizada, con la privación de estos derechos de amparo, se permite desconocer la protección estatal. Si eliminamos la naturaleza humana con la desaparición, eliminamos el sustrato de protección esencial de la convivencia humana que es el propio ser humano; justamente, el primer reparo al Estado es esa carencia de protección del ser humano que fue vulnerada.

Si partimos de este concepto, la desaparición forzada tiene una obligación no solo judicial, sino ética, con la sociedad, pues estos dos límites del amparo judicial y el conocimiento de los restos humanos de la víctima del delito permiten restaurar un orden social donde el primero en ser protegido es el ciudadano en su vida, honra y libertad, asunto que se desconoce con la desaparición forzada. ${ }^{17}$ En segundo lugar, para efectos de la jurisdicción especial para la paz (JEP) este elemento de judicialización se puede analizar desde la perspectiva del castigo y de la pena, pues estos no son los únicos factores que representan la justicia para este delito; en los actos de verdad, se representan las acciones de las FARC (Fuerzas Armadas Revolucionarias de Colombia) y los demás actores que se acojan al proceso. ${ }^{18}$

Sobre este punto es necesario observar que, independientemente de los resultados a los que se puede arribar, en el caso de la JEP, en este delito cobra importancia la verdad que, a su vez, también constituye un referente para dar lugar a los elementos

16 Kai Ambos y María Laura Böhm, Desaparición forzada de personas (Bogotá: Editorial Temis, 2009), 249; Sandoval y Durán, "La construcción", 5.

17 Sandoval y Durán, "La construcción", 6.

18 Jaime Sandoval y Álvaro Moreno, "Aspectos sociojurídicos de la justicia transicional en el proceso de paz en Colombia con las FARC" en Justicia constitucional para el posconflicto, comp. Dalia Carreño (Bogotá: Universidad Santo Tomás, 2018), 115. 
de juzgamiento de la JEP, sin contar con el valor que representa para la Unidad de búsqueda de personas dadas por desaparecidas, ya que esta documenta los casos y recoge la información sobre el delito y la JEP se encarga de judicializarlos y juzgarlos. A su turno, este elemento también daría insumos a la Comisión de la Verdad, pese a que no tendría relevancia judicial; ${ }^{19}$ sin embargo, a la postre, desde estos tres flancos, el proceso de judicialización también constituye un mecanismo de justicia.

El segundo factor en el delito de desaparición forzada proporciona un sistema de contexto para el descubrimiento y la revelación de los hechos. Por ejemplo, se pueden trazar los aspectos relacionados con los sucesos previos a la desaparición. Así, desde un punto de vista pragmático, se observan posibles tendencias de la razón de los sucesos que motivaron el delito. ${ }^{20}$ Se puede analizar si se trataba de un líder político importante o de un activista importante en materia de derechos humanos, de la sociedad civil, etc. y también si representaba un sector de la opinión como periodista, profesional liberal, etc. Si bien esto se puede identificar a primera vista, lo relevante es conocer cómo se accede a esta información y cómo se investiga este contexto que permita establecer los móviles de la desaparición. ${ }^{21}$

Los anteriores factores nos muestran que, además de estas actividades de investigación, la sociedad puede encontrar razones que aborda Sandel, tales como disculpas y reparaciones en la vida pública. ${ }^{22}$ Se trata de un proceso de expiar los pecados de los predecesores en la historia, de situarse frente al individualismo moral superponiendo los deberes de pertenecer a una comunidad, ${ }^{23}$ para aceptar delitos de lesa humanidad como la desaparición forzada, reparar la verdad hallada en estas pesquisas y continuar con la superación del pasado.

Independientemente de los procesos de implementación de la jurisdicción especial para la paz (JEP), con la Ley 1957 de 2019, lo relevante es que su orientación debe centrarse un poco más en la integración de los principios procesales penales, sobre todo, en este delito, en el que se requiere una concentración mayor de los hechos

\footnotetext{
19 Jaime Sandoval y Carlos Cárdenas, "Los principios de la justicia especial para la paz en los acuerdos suscritos con las FARC en Colombia y su relación con la Comisión de la Verdad", Revista de la Secretaría del Tribunal Permanente de Revisión del Mercosur 8, núm. 15 (marzo 2020): 77.

20 Sandoval y Durán, "La construcción", 5-7.

21 Sandoval y Durán, "La construcción", 6-7.

22 Sandel, Justicia, 236 y ss.

23 Sandel, Justicia, 236 y ss.
} 
para determinar el proceso del que fue objeto la víctima, desde que se retiene ilegalmente hasta que ya no se conoce más sobre su paradero. ${ }^{24}$

Sin duda, este factor, tanto procesal como probatorio, es necesario para analizar no solo un caso de desaparición forzada, sino para determinar una línea de contexto que puede señalar una política sistemática y generalizada de conducta que además de establecer la posibilidad de tratarse de un delito de lesa humanidad, también muestra la posibilidad de identificar un patrón de conducta significativo en la construcción de los insumos para decidir sobre el sistema especial de la jurisdicción para la paz.

\section{El análisis del contexto de la desaparición forzada}

En términos concretos, los elementos de contexto aparecen desarrollados inicialmente en Ramelli, quien afirma que los elementos que se aprecian en el lugar donde ocurren las situaciones asociadas a conductas penales revelan elementos para calificar las conductas. ${ }^{25}$ Pueden concurrir conductas asociadas a crímenes de guerra y lesa humanidad, de acuerdo con los elementos de contexto o concurrentes al conflicto. En su criterio, se debe establecer un parámetro diferenciador según el país, la región, las cadenas de mando, la organización, etc. ${ }^{26}$ Todo ello apunta a reconocer el patrón de políticas sistemáticas y generalizadas de estos delitos, más aún al tratarse del delito de desaparición forzada. ${ }^{27}$

Si nos detenemos en este aspecto, desde la perspectiva de Sandel encontramos un factor que él denomina la justicia y el bien común. Este análisis de contexto comentado revela unos factores de investigación asociados a bienes superiores, que deben ser abordados en esta tarea que favorece el rol de las víctimas, como lo establece el Artículo 1 de la ley de implementación de la JEP (Ley 1957 de 2019). Además, se reafirma este concepto que deriva de la dignidad humana que, en palabras de Sandel, deviene del bien común, que lo conforman bienes materiales y espirituales, así como bienes que podríamos denominar superiores (los morales y espirituales).

24 César Niño, "Exportación de conocimiento: Colombia como proveedor de seguridad para la lucha contra el terrorismo y el crimen internacional", Via Inveniendi et Iudicandi 11, núm. 2 (septiembre 2016): 95, https:// revistas.usantotomas.edu.co/index.php/viei/article/view/3277 (acceso enero 3, 2018).

25 Alejandro Ramelli, Jurisprudencia penal internacional aplicable en Colombia (Bogotá: Universidad de los Andes, 2011), 132

26 Ramelli, Jurisprudencia, 260.

27 Sandoval y Durán, "La construcción", 6-7. 
En este aparte es posible hacer un paréntesis, pues la simbología del autor comentado lo amerita. En cuanto a valores superiores que se contemplan en el valor de la justicia, sobre todo, en el tema analizado, Sandel lo expresa así:

El problema estriba en imaginar una política que tome las cuestiones morales y espirituales en serio [...]. Por ejemplo, la voz más prometedora fue la de Robert F. Kennedy en su nominación presidencial de 1968. Para él, la justicia suponía más que el volumen y la distribución del producto nacional: tocaba también propósitos morales superiores. ${ }^{28}$

Esto es lo que debemos observar en la desaparición forzada: se trata de un factor moral, pues esta conducta se observa tan relevadora en la restauración social del conflicto, que muchos casos son advertidos en Colombia casi desde los años setenta hasta la actualidad, muchos en la impunidad y sin acción judicial. Podemos consultar el informe sobre desaparición forzada de 2016, denominado Hasta encontrarlos, que revela que, de las 60630 víctimas de desaparición forzada en este momento, se sabe del paradero o la suerte de 8122 , lo que equivale a un 13,4\% del total de las personas desaparecidas forzadamente. ${ }^{29}$ Estos hechos fueron confesados en el marco de la Ley de 975 de 2005. En el pasado proceso de justicia transicional y en el nuevo proceso de paz, se analiza un universo de más de 120000 personas desaparecidas con datos actuales de alrededor de más de 7000 solicitudes de búsqueda de desaparición forzada. ${ }^{30}$

Basados en estas citas, nos atrevemos a decir que la desaparición forzada atenta contra bienes no solo materiales (la vida física), sino espirituales (no mentir) y, entre ellos, "propósitos morales superiores" (la paz, la solidaridad...). Como puede verse, la tarea de cumplir con estos bienes espirituales sociales es descomunal frente a la cifra de desaparecidos del conflicto. Así, se necesitan articulaciones institucionales con los organismos judiciales y la sociedad, para vincular al Estado en el cumplimiento de estos deberes y valores superiores. Se trata de ligar las consideraciones éticas que nos preceden con el derecho que consagra esos parámetros en normas positivas, como es el derecho internacional de los derechos humanos. De este modo, siguiendo

Sandel, Justicia, 296 y 297.

29 Centro Nacional de Memoria Histórica, Hasta encontrarlos: el drama de la desaparición forzada en Colombia (Bogotá: Imprenta Nacional, 2016), 87.

30 Unidad de búsqueda de personas dadas por desaparecidas, Informe de actividades de búsqueda, localización, recuperación, identificación y entrega digna. Fecha de corte: 30 de septiembre de 2020, https://www.ubpdbusquedadesaparecidos.co/actualidad/conozca-el-informe-de-actividades-de-la-unidad-de-busqueda-de-personasdadas-por-desaparecidas/ (acceso noviembre 19, 2020). 
las ideas madre de este capítulo, censurar la desaparición forzada es salvaguardar la justicia y el bien común, más aún frente a un panorama tan complejo como el mostrado en el caso colombiano, dado el gran número de víctimas. Miradas las cosas panorámicamente, método de nuestra predilección para el análisis de la realidad general y, por supuesto, de la ética, se puede concluir que la desaparición forzada no encuentra asidero ético adecuado en el pensamiento sandeliano expuesto, al cual nosotros queremos sumarnos mediante la reflexión a la qué nos ha invitado y presentado en este ex cursus. ${ }^{31}$

Estos elementos, junto con los desarrollos de los análisis de contexto y los de la justicia transicional, implican una responsabilidad y un compromiso de todos los actores judiciales, sobre todo, de la JEP, que requieren de concreción en el momento de judicialización de las conductas de lesa humanidad y, en concreto, con los delitos de desaparición forzada. ${ }^{32}$

De acuerdo con el punto anterior, el fin primordial de la justicia transicional es el aseguramiento de la justicia y de la paz, en aras de una verdadera "reconciliación de la sociedad y el fortalecimiento del Estado de derecho". ${ }^{33}$ Si tomamos en cuenta la reflexión ética que antecede en el crimen analizado, la responsabilidad es mayor y los resultados deben ser evidenciados a la sociedad. Recordemos que muchos de estos casos involucran a líderes sociales y actores que afectan a la sociedad civil. ${ }^{34}$

Desde la comprensión de la justicia transicional:

[...] no basta con que quienes hayan perpetrado violaciones a los derechos humanos sean castigados, sino que — desde la consideración de la necesaria re-dignificación de las víctimas y la importancia de que dichas violaciones no

31 Santiago Patarroyo y Paola Benavides, "Rupturas asignificantes: revisiones críticas en torno al derecho", Via Inveniendi et Iudicandi 9, núm. 1 (julio 2014): 9, https://revistas.usantotomas.edu.co/index.php/viei/article/ view/1337 (acceso enero 3, 2018)

32 Sonia Cortés, "Derechos humanos en las políticas de paz y posconflicto en Colombia", Via Inveniendi et Iudicandi 11, núm. 1 (junio 2016): 132, http://revistas.usantotomas.edu.co/index.php/viei/article/view/2926/2798 (acceso enero 3, 2018).

33 Ezequiel Malarino, "Argentina" en Desaparición forzada de personas: análisis comparado, coord. Kai Ambos (Bogotá: Temis, 2009), 301; Sandoval y Durán, "La construcción", 6-7.

34 Daniel Barragán, "La construcción de la mentalidad democrática como necesidad en el posconflicto", Via Inveniendi et Iudicandi 11, núm. 1 (junio 2016): 54, https://revistas.usantotomas.edu.co/index.php/viei/ article/view/2929 (acceso marzo 3, 2019). 
vuelvan a repetirse- se hace necesaria, además, la articulación de mecanismos de esclarecimiento de la verdad y reconstrucción de la memoria histórica. ${ }^{35}$

Este factor puede servir de elemento reparador; sin embargo, es necesario analizar los componentes que han sido construidos en los doce años de justicia transicional en el plano nacional, máxime frente al caso particular de la desaparición forzada, que tiene términos necesarios para resarcir la memoria de las víctimas. ${ }^{36}$ En el mismo sentido se han descrito mecanismos especiales de la justicia especial para la paz. ${ }^{37}$

\section{Conclusiones}

De acuerdo con Michael Sandel, es necesario determinar los que se consideran valores necesarios de imperativo cumplimiento, en particular, en materia de justicia. Es preciso reconocer la violación de valores esenciales de la sociedad, como en la desaparición forzada. Con más razón se erigen fundamentos necesarios para buscar la represión, prevención y reparación de las víctimas.

En segundo lugar, este delito se asocia al cumplimiento ético de valores tanto individuales como universales sobre el respeto y la protección de la persona en su dignidad humana. El resarcimiento de la memoria perdida en la desaparición forzada implica la obligatoriedad de su persecución y judicialización, porque se afectan no solo la libertad y la vida de una persona, sino la de toda la sociedad.

En cuanto a los deberes de judicialización y castigo, el compromiso con la sociedad es mayor en el caso de la desaparición forzada, toda vez que se afectan estos valores individuales y también los bienes espirituales superiores de carácter moral que, en definitiva, aseguran el bien común de la sociedad. De allí el deber estatal de proteger el amparo judicial de la persona, que constituye el primer bien jurídico que se afecta con la privación ilícita de la libertad por la desaparición forzada.

35 Javier Dorado, "Justicia transicional", Eunomía: Revista en Cultura de la Legalidad, núm. 8 (marzo-agosto 2015): 196; Sandoval y Durán, "La construcción", 6-7.

36 Sandoval y Durán, "La construcción", 6-7.

37 Colombia, Corte Constitucional, Sentencia C-370 del 18 de mayo de 2006, M. P. Manuel José Cepeda Espinosa, Jaime Córdoba Triviño, Rodrigo Escobar Gil, Marco Gerardo Monroy Cabra, Álvaro Tafur Galvis y Clara Inés Vargas Hernández; Sentencia C-080 del 15 de agosto de 2018, M. P. Antonio José Lizarazo Ocampo; Sentencia C-112 del 13 de marzo de 2019, M. P. José Fernando Reyes Cuartas; Colombia, Congreso de la República, Ley 1922 de 2018, "Por medio de la cual se adoptan unas reglas de procedimiento para la Jurisdicción Especial para la Paz" (Bogotá: Diario Oficial núm. 50 658, 18 de julio de 2018); Ley 1957 de 2019, "Estatutaria de la Administración de Justicia en la Jurisdicción Especial para la Paz" (Bogotá: Diario Oficial núm. 50 976, 6 de junio de 2019). 
Por último, en el contexto de recuperación de la memoria de las personas objeto de la conducta analizada, con la judicialización de la desaparición forzada, se asegura la obligación estatal de persecución, que es uno de los factores éticos del Estado; a la postre, esta trae como consecuencia la reparación de la paz y la solidaridad social en los bienes superiores que se exigen en estos casos, desde la postura de Michael Sandel.

\section{Referencias}

Alexy, Robert. La institucionalización de la justicia. 3a ed. Granada: Comares, 2005.

Ambos, Kai y María Laura Böhm. Desaparición forzada de personas. Bogotá: Editorial Temis, 2009. Barragán, Daniel. "La construcción de la mentalidad democrática como necesidad en el posconflicto". Via Inveniendi et Iudicandi 11, núm. 1 (junio 2016): 37-57, https:// revistas.usantotomas.edu.co/index.php/viei/article/view/2929 (acceso marzo 3, 2019).

Centro Nacional de Memoria Histórica. Hasta encontrarlos: el drama de la desaparición forzada en Colombia. Bogotá: Imprenta Nacional, 2016.

Colombia, Congreso de la República. Ley 1922 de 2018, "Por medio de la cual se adoptan unas reglas de procedimiento para la Jurisdicción Especial para la Paz”. Bogotá: Diario Oficial núm. 50 658, 18 de julio de 2018.

Colombia, Congreso de la República. Ley 1957 de 2019, "Estatutaria de la Administración de Justicia en la Jurisdicción Especial para la Paz". Bogotá: Diario Oficial núm. 50 976, 6 de junio de 2019.

Colombia, Congreso de la República. Ley 975 de 2005, "Por la cual se dictan disposiciones para la reincorporación de miembros de grupos armados organizados al margen de la ley, que contribuyan de manera efectiva a la consecución de la paz nacional y se dictan otras disposiciones para acuerdos humanitarios". Bogotá: Diario Oficial núm. 45980,25 de julio de 2005.

Colombia, Corte Constitucional. Sentencia C-080 del 15 de agosto de 2018. M. P. Antonio José Lizarazo Ocampo.

Colombia, Corte Constitucional. Sentencia C-112 del 13 de marzo de 2019. M. P. José Fernando Reyes Cuartas.

Colombia, Corte Constitucional. Sentencia C-370 del 18 de mayo de 2006. M. P. Manuel José Cepeda Espinosa, Jaime Córdoba Triviño, Rodrigo Escobar Gil, Marco Gerardo Monroy Cabra, Álvaro Tafur Galvis y Clara Inés Vargas Hernández.

Corte Interamericana de Derechos Humanos. Cuadernillo de jurisprudencia de la Corte Interamericana de Derechos Humanos $N^{o}$ 6: desaparición forzada. San José: Autor, 2020. 
Corte Interamericana de Derechos Humanos. Sentencia del 14 de noviembre de 2014. Caso Rodríguez Vera y otros (desaparecidos del Palacio de Justicia) vs. Colombia.

Cortés, Sonia. "Derechos humanos en las políticas de paz y posconflicto en Colombia". Via Inveniendi et Iudicandi 11, núm. 1 (junio 2016): 129-145, http://revistas.usantotomas. edu.co/index.php/viei/article/view/2926/2798 (acceso enero 3, 2018).

Dorado, Javier. "Justicia transicional". Eunomía: Revista en Cultura de la Legalidad, núm. 8 (marzo-agosto 2015): 192-204.

Malarino, Ezequiel. "Argentina” en Desaparición forzada de personas: análisis comparado, coordinado por Kai Ambos, 5-36. Bogotá: Temis, 2009.

Niño, Cesar. "Exportación de conocimiento: Colombia como proveedor de seguridad para la lucha contra el terrorismo y el crimen internacional". Via Inveniendi et Iudicandi 11, núm. 2 (septiembre 2016): 87-104, https://revistas.usantotomas.edu.co/index.php/ viei/article/view/3277 (acceso enero 3, 2018).

Patarroyo, Santiago y Paola Benavides. "Rupturas asignificantes: revisiones críticas en torno al derecho". Via Inveniendi et Iudicandi 9, núm. 1 (julio 2014): 7-31, https://revistas. usantotomas.edu.co/index.php/viei/article/view/1337 (acceso enero 3, 2018).

Ramelli, Alejandro. Jurisprudencia penal internacional aplicable en Colombia. Bogotá: Universidad de los Andes, 2011.

República de Colombia. Constitución Política. Bogotá: Legis, 1991.

Saidiza, Hugo y Jorge Enrique Carvajal. "Crisis del Estado de derecho en Colombia: un análisis desde la perspectiva de la legislación penal”. IUSTA, núm. 44 (2016): 17-39, https://revistas.usantotomas.edu.co/index.php/iusta/article/view/3074 (acceso enero 3, 2018).

Sandel, Michael. Justicia. ¿Hacemos lo que debemos? Barcelona: Debate, 2011.

Sandoval, Jaime y Álvaro Moreno. "Aspectos sociojurídicos de la justicia transicional en el proceso de paz en Colombia con las FARC" en Justicia constitucional para el posconflicto, compilado por Dalia Carreño, 123-152. Bogotá: Universidad Santo Tomás, 2018.

Sandoval, Jaime y Carlos Cárdenas. "Los principios de la justicia especial para la paz en los acuerdos suscritos con las FARC en Colombia y su relación con la Comisión de la Verdad". Revista de la Secretaría del Tribunal Permanente de Revisión del Mercosur 8, núm. 15 (marzo 2020): 71-91.

Sandoval, Jaime y Juan Durán. "La construcción del contexto en los elementos del crimen de desaparición forzada. Interpretación de la norma interna e internacional”. Proyecto para el fomento de la investigación y la innovación, Universidad Santo Tomás, 2019. Unidad de búsqueda de personas dadas por desaparecidas. Informe de actividades de búsqueda, localización, recuperación, identificación y entrega digna. Fecha de corte: 30 de septiembre de 2020, https://www.ubpdbusquedadesaparecidos.co/actualidad/conozca-el-informede-actividades-de-la-unidad-de-busqueda-de-personas-dadas-por-desaparecidas/ (acceso noviembre 19, 2020). 